\title{
Topical steroid, cyclosporin A, and the outcome of rat corneal allografts
}

\author{
K A Williams, S A ERICKSON, And D J COSTER \\ From the Department of Ophthalmology, Flinders University of South Australia, Adelaide, Australia
}

\begin{abstract}
SUMMARY The effects of a combination of topical corticosteroid and cyclosporin A on corneal graft survival were tested in a model of penetrating keratoplasty in the inbred rat. Topical medications were applied four times daily to the graft for 28 days postgraft. Neither topical steroid (1\% prednisolone acetate) nor topical cyclosporin (1\% in chremophor EL/ethanol) was able to modify the overall incidence of rejection, though all steroid-containing medications delayed the onset of rejection significantly. The combined formulation of steroid plus cyclosporin A caused a reduction in the incidence of rejection which did not reach statistical significance and which did not eliminate the response in all animals. The chremophor/ethanol vehicle was reasonably well tolerated but did cause some periocular dermatitis.
\end{abstract}

Despite intensive treatment with topical corticosteroids many corneal grafts performed in patients with pre-existing corneal vascularisation or a history of anterior segment inflammation will fail from rejection.' Because blindness is not a life-threatening disorder, the risks of morbidity and death associated with the systemic administration of non-specific immunosuppressive agents are seldom considered to be justifiable in corneal transplantation. Topical steroid is a relatively safe and effective immunosuppressive drug for corneal transplantation in the subgroup of patients with diseased but avascular, non-inflamed corneas. However, when the recipient cornea is vascularised, or the eye inflamed at the time of surgery, maximal doses of topical corticosteroid will not always prevent rejection. There is clearly a need, therefore, for an improved regimen of topical immunosuppression for high-risk patients with vascularised and inflamed eyes.

Topical cyclosporin A has been shown to prolong the outcome of corneal grafts in the rabbit, ${ }^{23}$ but a comparative study of the effects of short-term topical steroid and cyclosporin $\mathrm{A}$ in a rabbit model in which the recipient cornea was vascularised and inflamed showed that the conventional treatment, topical steroid, was more effective than cyclosporin A in prolonging corneal graft survival. ${ }^{4}$ Furthermore, Mannis and May reported similar findings when

Correspondence to Dr K A Williams, Department of Ophthalmology, Flinders Medical Centre, Bedford Park, SA 5042, Australia. comparing topical steroids with cyclosporin A administered by retrobulbar injection. ${ }^{5}$ However, the possibility that a combination of the two drugs might be more effective than either one or the other has not yet been examined. We have therefore tested the effects of short-term, topical administration of steroid, cyclosporin A, and a combination of the two in a model of penetrating keratoplasty in the inbred rat. Because of problems previously encountered by us and by others in the use of oily vehicles for topical administration of cyclosporin $\mathrm{A}$ to the rabbit eye, ${ }^{34}$ we elected to test an alternative vehicle, $70 \%$ chremophor EL/30\% ethanol. This has previously been reported by Wiederholt and his associates to be well tolerated by the rabbit. ${ }^{6}$

\section{Material and methods}

Animals. Female 12-week-old Fisher 344 and DA rats were used as recipients and donors, respectively.

Topical medications. Prednisolone acetate, $1 \%$ $w / v$ (Prednefrin Forte) was chosen as the topical corticosteroid because this formulation is frequently used in clinical practice. Cyclosporin A (Sandoz) was dissolved in a vehicle of $70 \% \mathrm{v} / \mathrm{v}$ chremophor EL (BASF) $/ 30 \% \mathrm{v} / \mathrm{v}$ ethanol and filtered through a $0.22 \mu \mathrm{m}$ Millipore membrane before use. A combined formulation was prepared by mixing the steroid and cyclosporin A solutions to yield a $0.5 \% \mathrm{v} / \mathrm{v}$ preparation of each. Medications were 
routinely stored at $4^{\circ} \mathrm{C}$ but were warmed to ambient temperature and shaken vigorously before use.

Rat corneal grafts. Penetrating grafts $3 \mathrm{~mm}$ diameter were performed in prevascularised eyes as previously described. ${ }^{7}$ Graft sutures were not removed postoperatively.

Treatment protocol. Five experimental groups were set up, each containing 10-15 recipients: no treatment, treatment with chremophor EL/ethanol vehicle, steroid, cyclosporin $A$ in vehicle, and the combined preparation. One drop of the appropriate medication was applied to the graft in the immediate postoperative period and then four times daily for 28 days postgraft. Animals were killed at day 60 postgraft.

Graft assessment. Grafts were examined under the operating microscope at 24 hours and three times weekly thereafter. The observer was unaware of the treatment applied to the rats being scored. Grafts were scored on a 0-3 scale for oedema, clarity, inflammation, and vascularisation, with 0 representing a perfect graft, that is, a non-oedematous, perfectly clear graft in an uninflamed eye, with no vessels (or ghost vessels only) crossing the host-graft margin. A score of 3 represented a thick, opaque graft, heavily vascularised, in an inflamed eye.

Histology. All grafts were taken for endpoint histological examination. Kidney and liver were also removed from some animals. Buffered formalinfixed tissue was embedded in JB4 resin and $2 \mu \mathrm{m}$ thick sections were stained with haematoxylin and eosin.

\section{Results}

Acceptability of the chremophor EL/ethanol vehicle in the rat eye was tested in a pilot experiment, in which rats bearing corneal isografts were treated four times daily for 28 days postgraft. The vehicle was

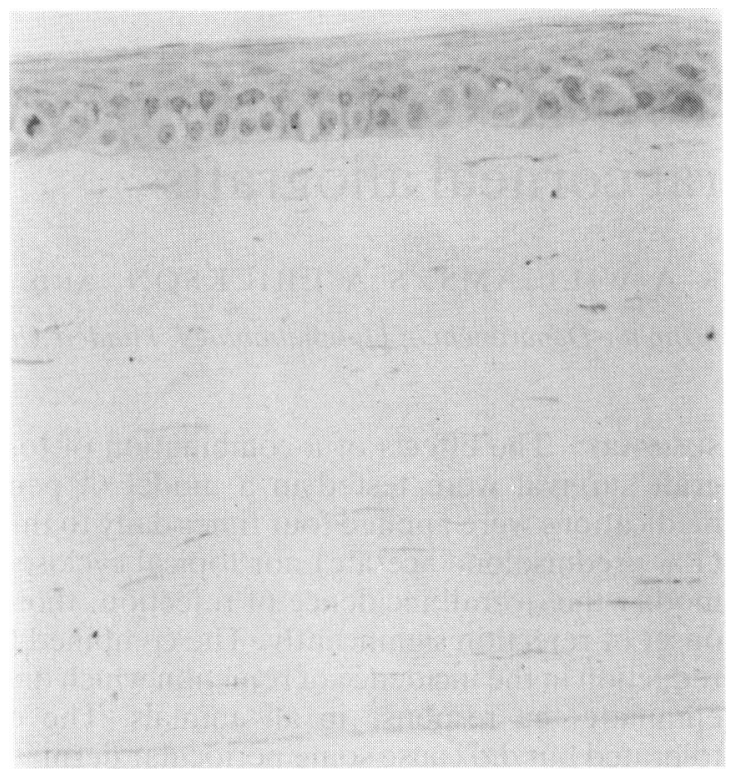

Fig 1 Histological section of rat corneal isograft from animal treated with chremophor EL/ethanol.

quite well tolerated, and endpoint histology of the grafts was unremarkable (Fig. 1).

The outcome of corneal allografts in the five experimental groups is presented in Table 1. Approximately $80 \%$ of control allografts underwent an episode of graft opacification (usually partial) with oedema, inflammation, and neovascularisation, considered to reflect rejection. Graft scores for these rejected corneas ranged from 1 to 3 .

None of the three regimens of drug treatment tested was able to modify the overall incidence of rejection to a significant extent. The combination of topical steroid plus cyclosporin A caused a reduction in the incidence of rejection that reached significance

Table 1 Incidence of rejection, median day to rejection, and weight gain between end of treatment period and end of observation period in rats with corneal allografts: effect of various regimens of topical immunosuppression

\begin{tabular}{|c|c|c|c|c|c|c|}
\hline \multirow[t]{2}{*}{ Group } & \multirow[t]{2}{*}{ Topical medication } & \multirow[t]{2}{*}{ Number } & \multirow{2}{*}{$\begin{array}{l}\text { Number with } \\
\text { rejection } \\
\text { episode }\end{array}$} & \multicolumn{2}{|c|}{ Median day to rejection } & \multirow{2}{*}{$\begin{array}{l}\text { Weight } \\
\text { increase }(\mathrm{g}) \text {, } \\
\text { day } 28-60 \\
\text { postgraft, } \\
\text { mean } \pm S D\end{array}$} \\
\hline & & & & All rats & $\begin{array}{l}\text { Excluding } \\
\text { non-rejected } \\
\text { grafts }\end{array}$ & \\
\hline 1 & No treatment & 15 & 13 & 8 & 7 & $14 \pm 6$ \\
\hline 2 & Chremophor/EL ethanol & 15 & 11 & 7 & 6 & $13 \pm 5$ \\
\hline 3 & $1 \%$ steroid & 9 & 6 & $15^{*}$ & $12 \dagger$ & $38 \pm 9 \ddagger$ \\
\hline 4 & $1 \%$ cyclosporin $\mathrm{A}$ & 13 & 12 & 7 & 7 & $10 \pm 5$ \\
\hline 5 & $\begin{array}{l}\text { Combination of } 0.5 \% \text { steroid plus } \\
0.5 \% \text { cyclosporin } \mathrm{A}\end{array}$ & 11 & 5 & $60^{*}$ & $9+$ & $39 \pm 12 \ddagger$ \\
\hline
\end{tabular}

${ }^{*} \mathrm{p}<0.01$ cf groups 1 and 2

$\dagger \mathrm{p}<0.05$ cf groups 1 and 2

$\ddagger \mathrm{p}<0.001$ cf groups 1,2 and 4 
at the $5 \%$ level (Fisher's exact test, one-tailed) when compared with the no-treatment control group $(p=0.034)$ or the combined control groups (groups 1 plus $2, p=0.036$ ), but not when compared with the group receiving vehicle alone.

Both topical steroid and the combination of topical steroid and topical cyclosporin A were able to delay the onset of rejection to a significant extent when compared with either of the control groups or the cyclosporin A group (Mann-Whitney U test). The combined formulation appeared significantly better than steroid alone when all grafted animals were considered ( $p<0.02$, two-tailed), because the combination increased the proportion of animals not undergoing a rejection episode during the period of observation. When the latter group was excluded from the analysis, the combined medication was no better than the topical steroid.

Of the 78 rats grafted 15 were judged to be technical failures (four infections, four cataracts, three early anaesthetic deaths, and four poorly sutured grafts) and were excluded from all analyses. Infections and cataract formation were approximately evenly distributed over all groups.

An unexpected observation was that animals treated with steroid, either alone or in combination with cyclosporin $\mathrm{A}$, became anorexic and failed to thrive. The weights of these rats were significantly lower than those of animals in any other group ( $t$ test, $\mathrm{p}<0.01)$ at 28 days postgraft. Once medication was stopped, however, all animals in the two groups that had received steroid rapidly gained weight (Table 1 ), so that by 60 days postgraft there was no significant difference in mean weights among rats in any of the five groups.

Endpoint histological examination of all grafts was unremarkable. No evidence of nephrotoxicity or hepatotoxicity was found in sections of kidney and liver removed from a proportion of the animals that had received cyclosporin $A$.

\section{Discussion}

A major difficulty in the examination of factors affecting experimental corneal graft rejection lies with the absence of an entirely appropriate experimental model. Rabbit models are cumbersome, firstset corneal graft rejection can be induced reliably only if the recipient eye is prevascularised or an eccentric graft is performed, and inbred strains are not widely available. The vascularised inbred rat eye provides an alternative model, but is also less than ideal in that only $75 \%$ of animals in a strongly histoincompatible combination will undergo corneal graft rejection. Furthermore, rat endothelium has the capacity for extensive regeneration by mitosis as well as by cell enlargement and sliding, ${ }^{8}$ unlike human endothelium, in which the regenerative capacity is very low. ${ }^{9}$ Rabbit endothelium can also undergo mitosis, ${ }^{10}$ but an intact monolayer is more quickly re-established across a denuded rat cornea, probably because of the smaller size of the eye. Final graft outcome is thus an insensitive endpoint in the rat, and the incidence of rejection needs to be examined instead.

None of the regimens of topical medications tested was successful in abolishing corneal graft rejection in our model, despite the relatively high doses of drugs that were applied to the eye (approximately $10 \mathrm{mg}$ / $\mathrm{kg} / \mathrm{day}$, based on a drop volume of $25 \mu \mathrm{l}$ ). The combination of steroid and cyclosporin A significantly reduced the incidence of rejection compared with the use of either drug alone, but the biological effect was marginal, with $45 \%$ of animals receiving the combined medication still undergoing an episode of rejection.

Topical steroid had no significanct effect on the incidence of corneal graft rejection in this model, in contrast to the findings in the rabbit, where topical steroid is most effective ${ }^{4}$ However, rat corneal grafts treated with topical steroid (either alone or in combination with cyclosporin A) were less inflamed and less vascularised than grafts in other treatment groups. The model may thus reflect the situation in high-risk clinical cases with fair accuracy.

The choice of the best vehicle in which to dissolve a topical formulation of cyclosporine for experimental studies remains a problem. Previous studies have generally specified olive or arachis oil, but there is inevitable variation among different batches of these oils and both can act as ocular irritants. ${ }^{2411}$ The combination of chremophor EL/ethanol used in this work was tolerated remarkably well in the rat eye, with no obvious toxicity evident, but periocular dermatitis observed in previous studies with olive and arachis oils was again experienced with this vehicle.

The actual route and extent of absorption of medication applied topically to the eye in experimental animals deserve further attention. It was observed over the course of these experiments that the rats almost always rubbed their eyes and then licked their paws after a drop of any sort was applied to the grafted eye. Some of the formulations may thus have been absorbed orally, and in any event limited oral absorption might well be expected for any drug applied topically to the tear film because of overflow through the normal lacrimal drainage channels. The unexpected failure of steroid treated rats to gain weight while undergoing topical treatment may conceivably have reflected some oral absorption.

Within the constraints of the model our data indicate that a combination of topical cyclosporin A 
and steroid is unlikely to provide a significant therapeutic advance over topical steroid alone, the current mainstay of immunosuppression for corneal transplantation.

We thank $\mathrm{N}$ Robson and A Neville for technical assistance, $\mathrm{E}$ Andrea and W Laffer for editorial assistance.

This work was supported by grants from the ORIA, the Pank Ophthalmic Trust, and the NH and MRC (grant 850179).

\section{References}

1 Coster DJ. Factors affecting the outcome of corneal transplantation. Ann R Coll Surg Engl 1981; 63: 91-7.

2 Hunter PA, Wilhelmus KR, Rice NSC, Jones BR. Cyclosporin A applied topically to the recipient eye inhibits corneal graft rejection. Clin Exp Immunol 1981; 45: 173-7.

3 Hunter PA, Garner A, Wilhelmus KR, Rice NSC, Jones BR. Corneal graft rejection: a new rabbit model and cyclosporin $\mathrm{A}$. Br J Ophthalmol 1982; 66: 292-302.

4 Williams KA, Grutzmacher RD, Roussel TJ, Coster DJ. A comparison of the effects of topical cyclosporin and topical steroid on rabbit corneal allograft rejection. Transplantation 1985; 39: 242-4.

5 Mannis MJ, May WN. Suppression of the corneal allograft reaction: an experimental comparison of cyclosporin $\mathrm{A}$ and topical steroid. Cornea 1983; 2: 95-101.

6 Kana JS, Hoffmann F, Buchan R, Krolik A, Wiederholt M. Rabbit corneal allograft survival following topical administration of cyclosporin A. Invest Ophthalmol Vis Sci 1982; 22: 686-90.

7 Williams KA, Coster DJ. Penetrating corneal transplantation in the inbred rat: a new model. Invest Ophthalmol Vis Sci 1985; 26: 23-30.

8 Tuft SJ, Williams KA, Coster DJ. Endothelial repair in the rat. Invest Ophthalmol Vis Sci 1986; 27: 1199-1204.

9 Treffers WF. Corneal endothelial wound healing. Thesis, chapter 4. Nijmegen: Janssen Print, 1982.

10 Van Horn DL, Sendele DD, Seideman S, Buco PJ. Regenerative capacity of the corneal endothelium in rabbit and cat. Invest Ophthalmol Vis Sci 1977; 16: 597-613.

11 Shepherd WFI, Coster DJ, Chin Fook T, Rice NSC, Jones BR. Effect of cyclosporin A on the survival of corneal grafts in rabbits. Br J Ophthalmol 1980; 64: 148-53.

Accepted for publication 1 May 1986. 